\title{
Back in the forest
}

\section{Ichirou Karahara}

Department of Biology, Graduate School of Science and Engineering, University of Toyama, 3190 Gofuku, Toyama 930-8555, Japan. E-mail: karahara@sci.u-toyama.ac.jp, Fax: + 81-76-445-6549

Received on January 18, 2010; Accepted on February 12, 2010

Before starting to write this letter, I reviewed my message of a year ago and found that I described the global financial crisis and global climate crisis. Up to this time, I have not personally found any sign of recovery from the economic downturn nearby. My students are still having quite a lot of difficulty securing jobs. However, the newspapers mention some signs of recovery from the global financial crisis. Perhaps there is another crisis that should be addressed-one that shows no recovery? Recovery would seem to be almost impossible unless excess carbon dioxide were to vanish somehow from the atmosphere. I often wonder whether any good sign was forthcoming during 2009 for healing of the Earth from its climate crisis.

I did hear some interesting news about the Nobel Memorial Prize in Economic Sciences in 2009. One laureate of that prize, Dr. Elinor Ostrom, received it for her study of the management of common natural resources such as forests. Mr. Adam Smith, Editor-in-Chief of Nobelprize.org, says, "Her research reveals that in many, but not all, cases, allowing users to develop their own rules to regulate the use of common property results in the most efficient solution for managing those resources". This is intriguing to me. In my letter last year, I referred to the "Green New Deal"-an approach based on a standard market mechanism as an environmentally focused investment approach aimed at a sustainable and low-carbon world. On the other hand, the newly introduced management idea for natural resources might indicate a new solution for the climate crisis. That news appeared to be a good sign. However, 2009 eventually yielded only the "great disappointment" of the Copenhagen Climate Summit Meeting (COP15). The real world does not appear to be so easily manageable.

As for root studies, is there any movement? Yes. An important meeting for root researchers was convened in 2009: The Symposium on Root Research and Applications (Root RAP) held in Vienna (http://rootrap.boku.ac.at/). As a participant in this meeting, I found that many researchers who deal with tree roots were participating. This is also the case for recent meetings of Japanese Society for Root
Research (JSRR). Root studies are becoming more active back in the forest. There we will find some clues to the solutions to our looming climate crisis.

Regarding this Journal, we have entered the new term of 2010-2011. I have again been appointed to the position of Editor-in-Chief of the Plant Root for the new term by JSRR, with three new managing editors joining the Editorial Board. I want to express my gratitude to all authors for their contributions, all who have submitted manuscripts to this journal, and to our managing editors, subject editors, and reviewers. I would like to inscribe the Managing and Subject Editors' names of the 2008-2009 term here on their behalf.

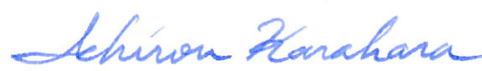

Ichirou Karahara Editor-in-Chief - Plant Root

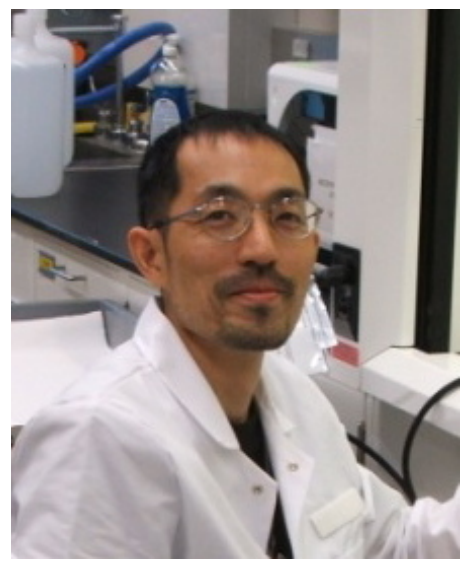

I. Karahara at Kennedy Space Center 


\author{
Editorial Board \\ January 2008 - December 2009 \\ January 2009 - December 2011 (As of January, 2010)
}

\section{Editor-in-Chief}

\section{Dr. Ichirou Karahara}

University of Toyama, Japan

\section{Managing Editors}

Dr. Jun Abe

The University of Tokyo, Japan

Dr. Hideki Araki

Yamaguchi University, Japan

Dr. Takuo Hishi [2008-2009]

Kyushu University, Japan

\section{Dr. Satoru Muranaka}

International Institute of Tropical Agriculture (IITA), Nigeria

Dr. Kyotaro Noguchi [2010-2011]

Forestry and Forest Products Research Institute, Japan

Dr. Nobuhito Sekiya [2010-2011]

JICA Tanzania Office, Japan International Cooperation Agency, Tanzania

Dr. Satoshi Shimamura [2010-2011]

National Institute of Crop Science, NARO, Japan

\section{Subject Editors}

\section{Dr. Peter W. Barlow}

University of Bristol, UK

Prof. Jiftah Ben-Asher

Ben Gurion University of the Negev, Israel

\section{Dr. Ivano Brunner}

Swiss Federal Institute for Forest, Snow and Landscape Research (WSL), Switzerland

\section{Dr. Hiroyuki Daimon}

Osaka Prefecture University, Japan

\section{Dr. Daniel K. Gladish}

Miami University, USA

\section{Dr. Hirokazu Higuchi}

Kyoto University, Japan

\section{Dr. Bingru Huang}

The State University of New Jersey, USA

\section{Dr. Osamu Ito}

Japan International Research Center for Agricultural Sciences (JIRCAS), Japan

Prof. Michael B. Jackson University of Bristol, UK
Dr. Maki Katsuhara

Okayama University, Japan

Prof. John Z. Kiss

Miami University, USA

Prof. Takayoshi Koike

Hokkaido University, Japan

Dr. Atsushi Kume

Kyushu University, Japan

Prof. Alexander Lux

Comenius University in Bratislava, Slovakia

Dr. Yoshiro Mano

National Institute of Livestock and Grassland Science, Japan

Prof. Shigenori Morita

The University of Tokyo, Japan

Dr. Toshifumi Murakami

National Agricultural Research Center for Tohoku Region, NARO, Japan

Dr. Akimasa Nakano

National Institute of Vegetable and Tea Science, NARO, Japan

\section{Dr. Yuka Nakano}

National Agriculture and Food Research Organization, Japan

Dr. Mizue Ohashi

University of Hyogo, Japan

Dr. Atsushi Oyanagi

National Institute of Crop Science, NARO, Japan

Dr. Loïc Pagès

Institut National de la Recherche Agronomique (INRA), France

Prof. Emeritus Thomas L. Rost

University of California, USA

Prof. Shinobu Satoh

University of Tsukuba, Japan

Prof. Lukas Schreiber

University of Bonn, Germany

Prof. Wendy K. Silk

University of California, USA

Prof. Hideyuki Takahashi

Tohoku University, Japan

Prof. Shuhei Tanaka

Yamaguchi University, Japan 
Prof. Eiichi Tanimoto

Nagoya City University, Japan

Prof. Philip White

Scottish Crop Research Institute, UK
Dr. Yajun Wu [2008-2009]

Utah State University, USA

Prof. Akira Yamauchi

Nagoya University, Japan

\section{Guest Editors}

January 2008 - December 2009

Dr. Gisela Grunewaldt-Stöcker

Leibniz University of Hannover, Germany

Dr. Yoshiaki Inukai

Nagoya University, Japan

\section{Dr. Junichi Kashiwagi}

International Crops Research Institute for the Semi-Arid Tropics (ICRISAT), India

Prof. Jiro Tatsumi

Kyoto Institute of Technology, Japan

Publisher: Japanese Society for Root Research 